\title{
TECHNOLOGY DEVELOPMENT IMPLEMENTATION OF CHANGES IN SMALL BUSINESSES STARTEGIC
}

\author{
Vlada Zivanovic, dipl.ecc. Master of Faculty of Economics, Belgrade \\ City Administration, Trg Slobode 3, 34000 Kragujevac, Serbia \\ Prof. dr. Nada Zivanovic, professor. \\ Faculty of Business and Industrial Management, University "Union" of Belgrade, Knez Viseslava 27, 11000 \\ Belgrade, Republic of Serbia \\ e-mail: profesorkanada@ yahoo.com
}

Marija Zivanovic dipl.ecc.doktorand of Faculty of Economics Kragujevac

City Administration, Trg slobode 3, 34000 Kragujevac, Serbia

\begin{abstract}
Small business development at the global level should be carried out continuously by continuous monitoring of international trends and developments in this area. Our Region is characterized by a lack of rapid development of small and medium enterprises. This paper presents the way of small business development new strategic change and modern development techniques.
\end{abstract}

Key words: Strategies, new changes, small busines, technology development, BPR -Business Process Reengineering

\section{INTRODUCTION}

New business processes on the small and medium-sized businesses require new tactics that are incorporated into planning decisions company, which essentially has to define the most important strategic goals. Business policy sets the principles conduct within a company and tactics make concrete instruments, measures, methods, techniques, technology, organization of work, etc.

The mere concretization implementation and development of these instruments for entrepreneurial activities are essential and are used primarily to meet the basic objectives of the enterprise.

In the example of the developed world companies, implementation and process improvements were made in small and medium-sized companies successfully implement organizational techniques, economic, quality system development techniques of TQM and reengineering as a key feature of economic development conditions.

For example, the implementation of Business Process Reengineering - BPR, is a business strategy and organization technique new management process, which was successfully implemented in the U.S. and other Western and international companies in the early 1990's. The focus is on the analysis and the design flow to improve business processes within manufacturing organizations. (Hammer, 1995)

The application of business process reengineering aims to solve the problems in key processes in organizations. This speaks, to the essence of entrepreneurial success in this business in a fundamental review of how to improve the quality of products and services to meet all customer requirements. With economic and technological aspects goal is to continuously introduce and maintain operational and economic costs. The bottom line is that the company is strategically directed towards the target, which will at all times be able to secure a leading position in the market world-class quality products and services. 
(JPMNT) Journal of Process Management - New Technologies, International

Vol. 1, No.3, 2013.

\section{STRATEGY DEVELOPMENT}

According to research, a planned development strategy of entrepreneurship in the Region Sumadija it is planned that the 2020 . process of improving efficiency and achieving notable places on the small and medium-sized enterprises should be realized through the implementation and development of modern techniques of world-class quality, reorganizing and redesigning business processes. The course development process improvement in small businesses can be implemented through four stages of development, including (Figure 1):
Phase I: Making strategic decisions for the planning and implementation of effective velopment process in every business and production activities by all employees.

Phase II: Analysis of the state of affairs after the implementation of new methods.

Phase III: Designing effective organization and implementation process.

Phase IV: Regular review of results achieved for continuous growth and development of quality business.

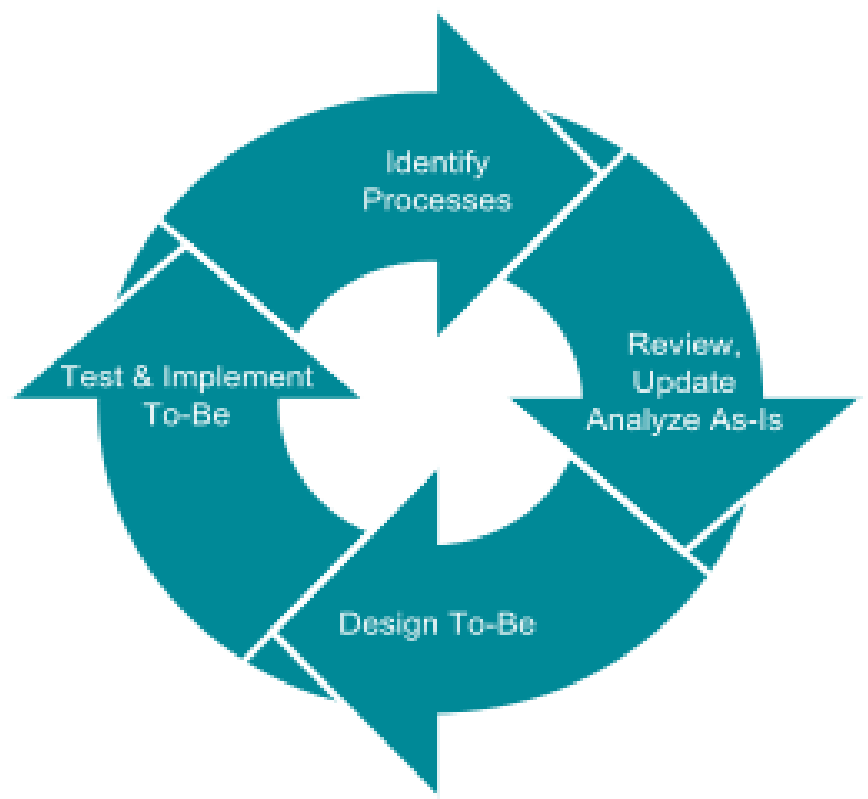

Business Process Reengineering Cycle

Figure 1. Course of the implementation of reengineering the process of efficient growth and development of small businesses 


\subsection{Why implement reengineering in small businesses globally?}

One of the main challenges for managers and management today, to overcome the traditional system of doing business that is, in practice the entrepreneurial process after replacing a bad good processes.

Replace the traditional and inefficient forms of organized labor who do not give a useful value of work, the use of new technology and technology, to use modern knowledge and know-how in automation and modernization work.

The idea, to plan and objectively consider, compare and analyze all production and business processes around the world have been adopted by a number of companies that seek to develop competitive potential, and also to restore competitiveness and to develop a new brand to meet today customers.

Data research scientists and pragmatists developed companies in the world, mostly in the field of entrepreneurship, to the point to realize management thinkers, the acceptance and development of business process reengineering as a new instrument for achieving success in a dynamic competitive market in the world in the coming years.

Commercial development of such pragmatic reengineering says (Porter, 1980), that is in 1993's. implemented to date in more than $60 \%$ of Fortune 500 companies.

According to the data, managers have initiated reengineering processes - (Business Process Reengineering - BPR) and strategic plans are set up to continue the process of being implemented.

Pragmatic and scientific application of the given concept for our Region means progress toward the identification of products and services in this area on the international market, which contributes to expand the spatial dimension to it. In particular, the development of new techniques on the one hand, it opens a new success in the expansion of supply, on the other hand, means the appearance and win new customers.
The fact is that economic globalization initiate new competitors, and managers are often insufficient for such ventures are ready to fully respond well to these challenges. This is the case in the analyzed region, where it is expected to quickly achieve greater management capacity of small and medium enterprises, to suppress competition in the global market, and affirmation, and attractive to producers in today's highly complex and demanding market and who seek to maintain their market position .

Studies show that the new business philosophy of business given techniques, such as reengineering of business processes in this region a relatively new phenomenon that conceives the essence of high-quality changes in the economic way of thinking management. With the implementation of new strategic business model will unexpectedly quickly be able to expect a great business results and challenges to further the policies of modern approaches.

Wrong approach to these boxes unchecked acceptance of practices that may be difficult to achieve development plan if your company today competitiveness based on a quick imitation of others' technological innovation. It happens, but rarely to the opposite set of correct practice, can lead to success and that some practices were able to quickly reach and sometimes exceed the level of beginners and innovators. (Zivanovic, N. 2002)

The fact is that in the region there are reasons for finding the key parameters that determine the operation of small businesses and their aspirations for market expansion, and when it comes to:

1) low labor cost

2) the willingness of firms to invest most of the profits in the knowledge, training and continuous learning.

According to this fact on the ground, we come to the view that the economic reality of dramatically changing rapidly, and that this is in fact the biggest challenge today for all managers and entrepreneurs and for all decision entrepreneurial, strategic and business decisions of corporate as well as macroeconomic. 
Reengineering is actually a fundamental rethinking and radical redesign of business processes to achieve dramatic improvements in critical points, ie. important measures of performance, such as cost of finished product / service to market, cost, quality and speed to achieve these parameters.

\section{INCORPORATING THEORETICAL APPROACH STRATEGIC CHANGE IN THE PRACTICE OF ENTREPRENEURIAL FIRMS IN THE REGION}

Implementing change and development using modern techniques in the practice of SME's refers to the deepest business and entrepreneurial changes, the most visible and often most difficult, and thus often the most severe (Dracher, 2005).

The concept of reengineering (Lukic, Zivanovic, 2009) requires that the first step of the implementation, set a strategic goal and significance of the changes, that asks what the company has to work, and then how is it that implemented. The entire flow things seen new business and manufacturing philosophy therefore refer to it, at the very beginning of the implementation of the activities, processes should replace bad with good, and in addition to concentrate on what it is to be as good as the out come of the entire work.

This amounts to knowledge management that the example of process reengineering - contains a significant measure of "strategic fundamentalism", which involves a radical redesign of existing structures to organize tasks and procedures, and to find and implement a completely new way of doing business in all functions of the company, from design production, to sales and after sales of products and services.

The process shows that the main objective of reengineering optimization of the efficiency and effectiveness of entrepreneurial activity.
Implementation of the new process reengineering includes:

- changes in organization and methods of work: from functional departments to work teams;

- changes in work content: from simple tasks to multi-dimensional, with the aim to raise the maximum level of use of working time;

- changes in the role of employees: from controlled to authorized actors;

- changes in preparation for work: the training (training) to education (how to why);

- changes in the measurement of operating performance that are expected as compensation: from activities to results;

- change the criteria progression: from performance to ability;

- changes in values and corporate culture: working with customers who are famous, old or win new customers and expand into new market areas, etc. Customers;

- changes in the role of managers: the supervisor to coach and mentor;

- changes in organizational structures: from hierarchical to flat with less hierarchical levels;

- changes in responsibilities executives: from the controller to the leader and others.

The basis is to understand the role of application cognition management team and a good knowledge of the methods of effective and economically reasonable quality, in the implementation of new techniques and making appropriate strategic decisions for the further advancement of entrepreneurship and entrepreneurial activity. 


\section{CONCLUSION}

Strategic decisions relating to how to generate and manage changes that affect all elements of the micro, meso and macro economic structure of modern societies.

Processes and initiates the necessary rapid changes in the environment, ie. introduction of so high technology in the process of achieving a technologically advanced enterprise, achieve the planned objectives.

In fact changes of previous models to improve business management contribute to increase the quality level of performance within their own enterprise economy in the Region.

This requires a greater investment of domestic and foreign investment, investment in know-how and new methods and techniques in new scientific knowledge, education and training of employees and other things that contribute to new business and economic growth.

Because of the speed change to be more and more quickly place in the business environment, which can occur under the influence of labor market conditions, operations and development of new techniques, technological processes, technologies, and processes of globalization, business process reengineering increasingly important.

From the above it follows that reengineering has to be driven by people with a wide knowledge, know-how, and their ability to monitor the new process of strategic change. In other words, reengineering is the responsibility of top management, which must be fully aware of the radical nature of moves to pull, weight and consequences that will occur at all, far reaching measures that make a long term in order to strengthen their own market position.

Analysis studies show that global business of small companies in the Region is not satisfactory as the world market demands. Only a good economic environment may create the conditions for entrepreneurial success and his favoring.
The data show that the success of small business companies in the world and in our country, in a homogeneous supra interact with specific economic environment, that determines the manner of its occurrence in the market.

It should be noted that the prevailing production and business relations of production, the most important determinant of any economic environment.

Data from the analysis of the world economic system in the late 90's and early this century, show that in this area, $30 \%$ of the world economy in an irrational manner accessed treatment market.

The strategic problem was the lack of involvement of top management and innovative work in the development of new techniques of growth and development of small businesses.

Organizational design and organizational climate and culture of small and medium-sized companies in an economic environment is a key factor in strategic operations, and in which context is defined business policies and business objectives.

Today's market increa singly focusing attention on the implementation of new management ideas for change. Changes should be directed to the implementation of new techniques and technologies. The solutions must ensure customer satisfaction in the market. Techniques reorganization of entrepreneurial business are imperative efficient operations of all companies in the world and in our country. 


\section{REFERENCES}

1. Hammer, M. Beyond (1995)., Reengineering, Harper Business, New York.

2. Zivanovic, N. (2002). Reengineering. Novi Sad, Faculty of Business Management.

3. Zivanovic, N., Lukic, S. (2009), Reengineering, Pan European University "'APEIRON", Banja Luka, Bosnia and Herzegovina, the Republic of Serbian

4. Porter, EM (1980)., Competitive strategy, New York: pp. 205

5. Lukic, S. Zivanovic, N. (2009), Business Process Reengineering, Banja Luka: Pan-European University '’Apeiron’’. pp. 55-56

6. Dracher, P. (2005), Management of the new company, Novi Sad:, Adizes, pp. 75

7. Đuričin, N., Janošević, VS, \& Kaličanin, Dj. M. (2009), Management and strategy, Belgrade: Center for Publishing, Faculty of Economics, Belgrade. pp.67, 315
8. Zivanovic, N., Zivanovic, V., \& Lukic, S. (2011), Affirmation of integrated quality management system in medium enterprises, Novi Pazar, International Conference SMEPP, International University of Faculty for management in traffic and communication Novi Pazar, Proceedings CIP the publication, the National Library of Serbia, Belgrade, 334.71 (082) 005 (082), ISBN 97886-84389 -26-0 (IU), COBISS.SR ID 185820 940

9. Zivanovic, N., Zivanovic, V., \& Todorova, D. (2010), Reengineering of business processes - strategy of turning point,. Sofia, Bulgaria, Scientific Magazine, International Conference, Academic Journal, Mechanics Transport Communications, ISSN 1312-3823, Article No. 0474, MTC device, Issue 2, uk-uk3.5 to 3.5 .

10. Zivanovic, N., \& Zivanovic, V. (2010, Effective organizational culture key successful business enterprises in transition, Sofia, Bulgaria, Scientific Magazine, International Conference, Academic Journal, Mechanics Transport Communications. ISSN 1312-3823, article no. 0473, MTC device, Issue 2, pp. uk to uk-3.1-3.4 